\title{
CARDIOTOXIC EFFECTS OF HALOPERIDOL AND CARDIOPROTECTION OF GINGER EXTRACT IN ADULT MALE ABINO RATS
}

\author{
ADEBISI BENJAMIN TEMIDAYO', FAMOYE, DAVID., TIAMIYU', AND OYENIKE, M.A² \\ DEPARTMENT OF ANATOMY, OSUN STATE UNIVERSITY, NIGERIA \\ 2DEPARTMENT OF MEDICAL LABORATORY SCIENCES, LADOKE AKINTOLA UNIVERSITY OF TECHNOLOGY, OSOGBO, \\ NIGERIA
}

\section{OBJECTIVES:}

There is evidence that cardiotoxicity can be induced by some antipsychotics that are D2 receptors antagonistic; there are also findings of antioxidants as cardioprotective agents.

Haloperidol has a D2 receptor antagonistic property, while ginger has abundance of antioxidants; therefore, it is important to evaluate the cardioprotective properties of these antioxidants in cardiotocixity induced by haloperidol.

\section{BACKGROUND AND AIMS:}

Haloperidol-induced oxidative stress causes cellular damage due o generation of free radical. The study determined the protective effects of ginger on histopathological changes in the myocardium, induced by haloperidol. This gives an insight to advise aged patients, with pre-existing heart conditions, that are given haloperidol as treatment for senile delirium.

\section{METHODS:}

Twenty adult male albino rats were subjected to experiment for 19 days. They were divided into four groups $(A, B, C, D)$. Group A received Normal saline, and served as the control group; Group $B$ received haloperidol at $1 \mathrm{mg} / \mathrm{kg}$ boy weight (b.w) of haloperidol. Group C received ethanolic extract of ginger at $100 \mathrm{mg} / \mathrm{kg}$ b.w, while Group D received ginger extract at 10omg/kg b.w Thirty minutes before administration of $1 \mathrm{mg} / \mathrm{kg}$ b.w. of haloperidol; thereafter, the animals were sacrificed and the hearts were excised by ventral thoracotomy.

The weights of the rats, at sacrifice, and the hearts were measured to determine the relative heart-body weight of rats to determine any correlation between haloperidol administration and the weight in the myocardial muscles and later, the hearts were processed for histological and histochemical procedures.

\section{RESULTS:}

There was no clear significant difference $(\mathrm{p}>0.05)$ in the mean relative heart-body weight of the control or experimental group, howbeit, myocardial muscles of Haloperidol-treated rats showed pathological changes in the form of degenerated and fragmented muscle fibres with vacuoles. Separated muscle fibers, with areas of myocytolysis can be seen, cardiomyocytes nuclei are small and pyknotic and karyorrhexic (nuclear fragmentation) and other nuclei areas faded out in the tissue sections. The blood vessels are seen to be congested with infiltration: there are also weak PAS reactions in degenerated muscle fibers and moderate in other cells. There was increased deposition of collagen fibers in between cardiac muscle and blood vessels. These pathological features were attenuated in rats co-administered with ginger and haloperidol

\section{CONCLUSION:}

Haloperidol causes myocardial damage in experimental rats. Ginger could be used as a protective agent against the long term use of haloperidol to ameliorate damaging effects on myocardial muscles.

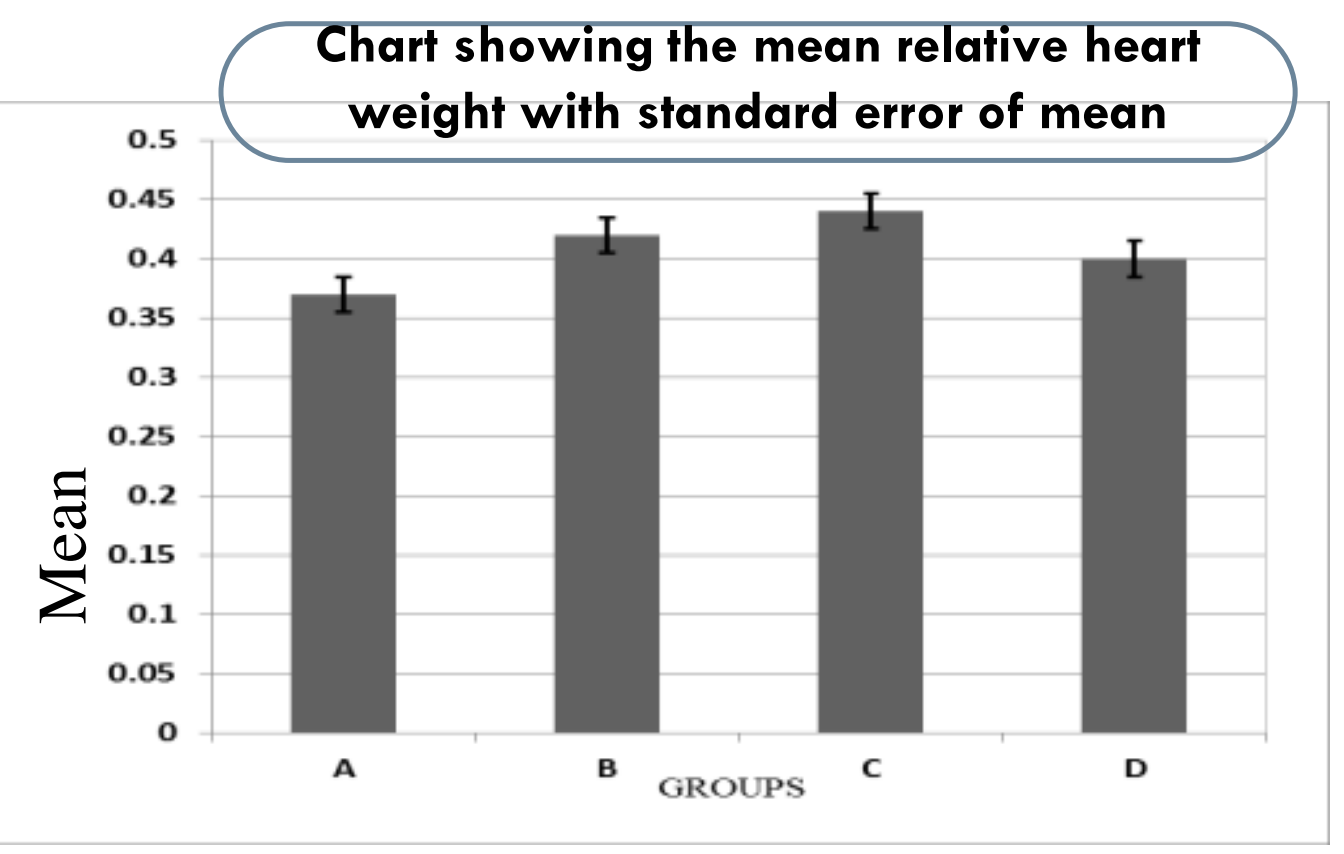

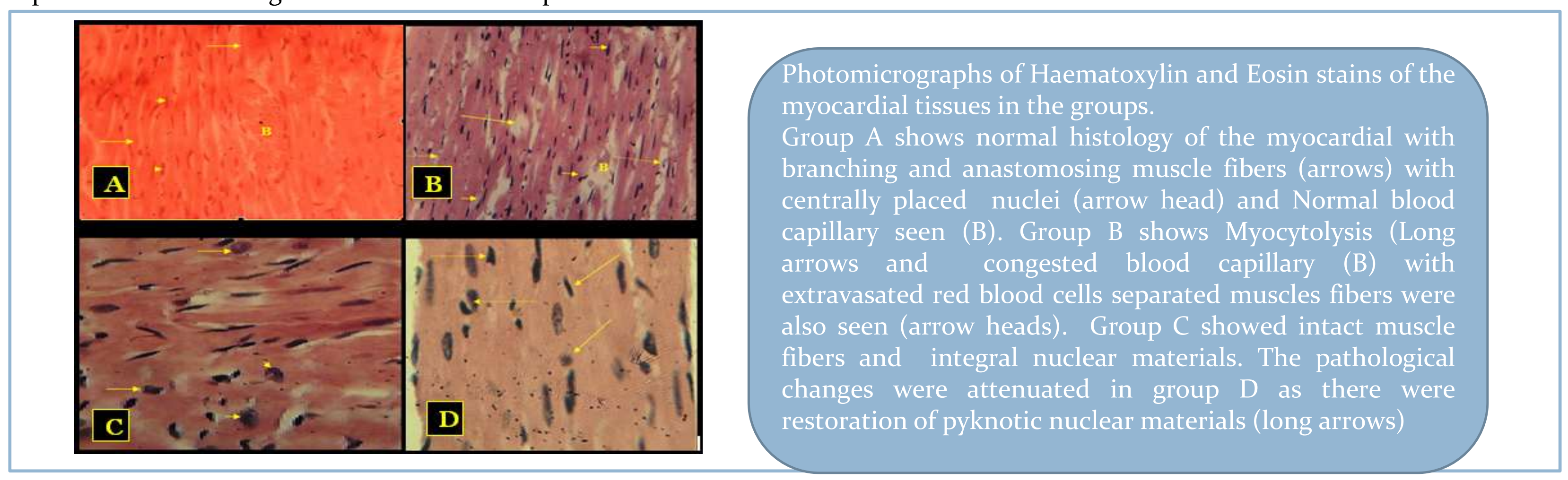

Photomicrographs of Haematoxylin and Eosin stains of the arrows and congested blood capillary (B) with extravasated red blood cells separated muscles fibers were also seen (arrow heads). Group C showed intact muscle fibers and integral nuclear materials. The pathological changes were attenuated in group D as there were restoration of pyknotic nuclear materials (long arrows) 